\title{
Low Incidence of ABL-Class And JAK-STAT Signaling Pathway Alterations In Uniformly Treated Pediatric And Adult B-Cell Acute Lymphoblastic Leukemia Patients Using MRD Risk-Directed Approach - A Population-Based Study
}

\author{
Rimvydas Norvilas ( $\square$ rimvydas.norvilas@santa.lt) \\ Vilnius University Hospital Santaros Klinikos https://orcid.org/0000-0002-8502-0750 \\ Vaidas Dirse \\ Vilnius University Hospital Santaros Klinikos \\ Ruta Semaskeviciene \\ Vilnius University Hospital Santaros Klinikos \\ Orinta Mickeviciute \\ Vilnius University Hospital Santaros Klinikos \\ Egle Gineikiene \\ Vilnius University Hospital Santaros Klinikos \\ Mindaugas Stoskus \\ Vilnius University Hospital Santaros Klinikos \\ Goda Vaitkeviciene \\ Vilnius University Hospital Santaros Klinikos \\ Jelena Rascon \\ Vilnius University Hospital Santaros Klinikos \\ Laimonas Griskevicius \\ Vilnius University Hospital Santaros Klinikos
}

Research article

Keywords: B-ALL, ABL-class, JAK-STAT, RNA-Seq

Posted Date: October 5th, 2020

DOI: https://doi.org/10.21203/rs.3.rs-73478/v1

License: (1) This work is licensed under a Creative Commons Attribution 4.0 International License. Read Full License

Version of Record: A version of this preprint was published at BMC Cancer on March 29th, 2021. See the published version at https://doi.org/10.1186/s12885-020-07781-6. 


\section{Abstract}

Background: ABL-class and JAK-STAT signaling pathway activating alterations have been associated with both poor post-induction minimal residual disease (MRD) response and inferior outcome in B-cell acute lymphoblastic leukemia (B-ALL). However, in most of the studies patients received non-uniform treatment.

Methods: We performed population-based analysis of 160 (122 pediatric and 38 adult) Lithuanian BCR-ABL 1-negative B-ALL patients who had been uniformly treated according to MRD-adapted NOPHO ALL-2008 protocol. Targeted RNA sequencing and FISH analysis was performed in cases without canonical B-ALL genomic alterations (high hyperdiploids and low hypodiploids included).

Results: We identified ABL-class fusions in $3(1.9 \%) B-A L L$ patients (exclusively in adults $(p=0.032)$ ). JAK-STAT pathway fusions were present in $4(2.5 \%)$ cases. Of note, P2RY8-CRLF2 fusion was absent in both pediatric and adult B-ALL cases. Patients with ABL-class or JAK-STAT pathway fusions had poor MRD response and were assigned to the higher risk groups, had worse event-free survival (EFS) and overall survival (OS) compared to patients without these fusions. In multivariate analysis, positivity for ABL-class and JAK-STAT fusions was a risk factor for worse EFS ( $p=0.043)$ but not for OS $(p=0.278)$ in adults.

Conclusions: We show low overall frequency of ABL-class and JAK-STAT fusions and the absence of P2RY8-CRLF2 gene fusion in the Lithuanian BCR-ABL 1 negative B-ALL cohort. Poor event-free survival in ABL-class / JAK-STAT fusion-positive adult patients despite MRDdirected therapy should be confirmed in future studies.

\section{Background}

B-cell acute lymphoblastic leukemia (B-ALL) is an aggressive and genetically heterogeneous disease which mostly affects children and young adults [1]. Genetics has been associated with the B-ALL outcome resulting in risk-adapted treatment protocols [2]. Approximately one-third of both pediatric and adult B-ALL cases do not harbor any canonical B-ALL genomic alterations [3]. Gene expression profiling (GEP) of B-ALL patients negative for canonical alterations identified a subgroup of patients characterized by similar expression profile to those harboring $\mathrm{t}(9 ; 22) / B C R-A B L 1$ (Philadelphia chromosome-like (Ph-like) or BCR-ABL 1-like B-ALL) $[4,5]$.

Whole transcriptome/exome sequencing and fluorescence in situ hybridization (FISH) analysis of Ph-like B-ALL samples revealed high frequency of genomic alterations disrupting the normal function of kinase and cytokine receptor signaling pathways of which $A B L-c l a s s$ kinase and JAK-STAT signaling pathway genes were most commonly affected [6]. ABL-class gene and JAK-STAT pathway alterations are associated with a high post-induction MRD levels, an increased relapse rate and inferior outcome. Of note, some of these gene fusions can be successfully targeted using small-molecule inhibitors $[7-9,38,39,40]$. The identification of Ph-like B-ALL signature is not standardized and both ABL-class and JAK-STAT fusions can also be found outside of Ph-like B-ALL group [10-12, 42]. High expression levels of CRLF2 gene and IKZF1 gene deletions are also common in Ph-like B-ALL subgroup resulting in worse outcome in some series [5, 13].

In most studies, Ph-like B-ALL was clinically characterized as a high-risk group with inferior overall survival in intensively treated children and adults [14-16]. In contrast, Ph-like B-ALL children did not have inferior survival when minimal residual disease (MRD)-directed treatment of Total Therapy XV protocol was used $[17,18]$. Whether MRD-directed treatment can also improve the negative prognosis of Ph-like B-ALL adult patients remains to be defined.

To characterize the incidence of ABL-class and JAK-STAT signaling pathway activating alterations in the Lithuanian population of consecutive B-ALL pediatric and adult patients and to determine their clinical significance, we performed a comparative genomic and clinical data analysis of patients uniformly treated using MRD-risk directed approach.

\section{Methods}

\section{Patients and samples}

From July 2008 to December 2017, pediatric (1-17 year-old) and adult (18-45 year-old) B-ALL patients who had been diagnosed with BCR-ABL 1-negative B-ALL in Lithuania and enrolled into NOPHO ALL-2008 clinical trial [2] were included. In addition, eleven 46-65 yearold adult patients had been treated according to NOPHO ALL-2008 protocol with chemotherapy dose modification and outside of the clinical trial. Patients' data were collected retrospectively. 
The diagnosis of ALL was based on a bone marrow biopsy or aspirate showing $\geq 20 \%$ leukemic blasts. The protocol specific genetic analysis was limited to canonical B-ALL genomic alterations: $\mathrm{t}(12 ; 21) / E T V 6-R U N X 1, \mathrm{t}(1 ; 19) / T C F 3-P B X 1,11 \mathrm{q} 23 /$ KMT2A gene rearrangements, iAMP21, dic(9;20), high hyperdiploidy (51-67 chromosomes) and low hypodiploidy (31-39 chromosomes). Cases without canonical B-ALL translocations were selected for RNA sequencing. Patients with ploidy shifts (high hyperdiploidy or low hypodiploidy) were also selected for RNA sequencing as they could harbor additional kinase and cytokine receptor signaling pathway alterations $[19,20]$.

Patients were stratified to the three risk groups defined in the NOPHO ALL-2008 protocol detailed elsewhere [2]. Stratifying factors were white blood cell count, immunophenotype, cytogenetics at diagnosis and treatment response defined as MRD. High genetic risk was assigned if KMT2A gene rearrangements, iAMP21, dic $(9 ; 20)$ or low hypodiploidy were present. The MRD analysis was performed on days 15, 29 and 79 (only for standard risk (SR) and intermediate risk (IR) patients) or after each block (in high-risk (HR) arm until MRDnegativity). If MRD was $\geq 0.1 \%$ on day 79 (SR and IR) or after block B1 (HR), patients were referred to allogeneic hematopoietic stem cell transplant (SCT) after receiving at least one additional block of therapy and having MRD below $<10^{-3}$ (optimally negative) (HR-SCT arm).

The study was conducted in accordance with the Declaration of Helsinki, and the protocol was approved by Vilnius Regional Bioethics Committee. The patients provided written informed consent. The waiver for obtaining written informed consent from patients who could not be reached despite best efforts had been approved by Vilnius Regional Bioethics Committee according to national regulations.

\section{RNA purification and targeted RNA-Sequencing}

Total RNA was purified from fresh bone marrow samples at the time of diagnosis using silica-membrane-based purification protocols and stored at $-80^{\circ} \mathrm{C}$. All bone marrow samples had blast counts $\geq 70 \%$. Before RNA sequencing (RNA-Seq), purified RNA concentration and quality was assessed using NanoDrop2000 spectrophotometer.

RNA-Seq libraries were constructed using Illumina TruSight Pan-Cancer sequencing kit (Illumina, San Diego, CA, USA), following the manufacturer's protocol and recommendations. A total of 1385 cancer-related genes were analyzed including the most mutated genes of ABL-class ( $A B L 1, A B L 2$, PDGFRB, CSF1R) and JAK-STAT (JAK1, JAK2, JAK3, CRLF2) signaling pathways. At least 4 million paired-end reads were obtained for each sample. NGS data analysis was performed using Illumina BaseSpace Informatics Suite (Illumina). TopHat/STAR aligners and Manta fusion caller were used to detect novel and recurrent gene fusions. At least one partner gene was required to detect novel gene fusion. Only high-confidence fusions were called that met threshold filters: split and paired unique reads ( $\geq$ 3 ), fusion contig align ( $\geq 16 \mathrm{bp}$ in length), coverage after fusion ( $\geq 100 \mathrm{bp}$ ), break end homology ( $\leq 10 \mathrm{bp}$ ).

Additional gene mutation analysis from RNA-Seq data was performed using GATK pipeline and Isaac Variant Caller 2.3. Point mutations and small indels were called if they had allele frequency $\geq 5 \%$ and population frequency $<0.01$, were negative for known SNP's and were previously described in genomic variant databases (COSMIC, ClinVar, etc.).

Prior to the study, RNA-Seq method was first validated using thirteen B-ALL control samples with previously identified gene fusions (BCR$A B L 1 \mathrm{n}=5, K M T 2 A$ gene rearrangements $\mathrm{n}=5, T C F 3-P B X 1 \mathrm{n}=2, E T V 6-R U N X 1 \mathrm{n}=1$ ). All in-frame gene fusions were identified, therefore RNA-Seq method was used for B-ALL study patients.

\section{FISH, PCR and SNP Array data analysis of B-ALL fusions}

Due to technical limitations of RNA-Seq, additional FISH analysis of CRLF2 gene (CRLF2 (Xp22/Yp11) Break / IGH Fusion,TC; Leica Biosystems, Wetzlar, Germany) was performed to identify P2RY8-CRLF2 and IGH-CRLF2 gene fusions. FISH analysis for ABL 1 (SPEC $A B L 1$ Dual Color Break Apart Probe; ZytoVision, Bremerhaven, Germany), ABL2 (SPEC ABL2 Dual Color Break Apart Probe; ZytoLight), JAK2 (JAK2 (9p24) Break; Leica Biosystems) and PDGFRB (PDGFRB (5q32) Break; Leica Biosystems) genes were used to confirm respective gene fusions detected by RNA-Seq method. FISH analysis was performed according to manufacturer protocols.

Standard PCR was used to confirm in-frame fusions that were not confirmed with additional FISH analysis. Fusion specific PCR primers were constructed for each case (Additional file 1: Table S1). Gene fusions were confirmed by gel electrophoresis and Sanger sequencing.

P2RY8-CRLF2 fusion is a result of $320 \mathrm{~Kb}$ size deletion of PAR1 region in the short arm of either $\mathrm{X}$ or $\mathrm{Y}$ chromosomes. We performed SNP Array data analysis for detection of PAR1 region deletions in order to confirm the absence of P2RY8-CRLF2 gene fusion not detected by RNA-Seq or FISH methods in our cohort. SNP-Array method was based on Infinium HD whole-genome genotyping assay with the HumanCytoSNP-12 BeadChip (Illumina Inc., San Diego, CA), which covers the entire genome with an average spacing of $9.6 \mathrm{~kb}$ and allows an average resolution of $31 \mathrm{~kb}$ was used for detection of PAR1 region deletion. 


\section{Statistical analysis}

Differences in the prevalence of parameters between the groups were performed using Mann-Whitney test or Independent-Samples T-test for continuous variables depending on their distributions. For categorical analyses, either a Chi-square or a Fisher exact test was used. Univariate and multivariate Cox proportional hazard regression models were used to evaluate the effect of non-canonical B-ALL genomic alterations on survival. The Kaplan-Meier method was used to estimate the time to event distributions (overall survival and event-free survival), the Log-Rank test was used to compare differences in survival curves. The overall survival (OS) was computed from the date of diagnosis until the date of death or last known follow-up date. The event-free survival (EFS) was defined as the time from diagnosis to the event of resistant disease, relapse, induction death, death in remission, second malignancy or date of the last follow-up if a patient had no events. A p-value $<0.05$ was considered to indicate statistical significance. Statistical analyses were performed using SPSS software version 20.

\section{Results}

\section{Study population}

Overall, one hundred and sixty 1-65 year old patients representing over $95 \%$ of the $B C R-A B L 1$ negative B-ALL patient population in Lithuania during July 2008 - December 2017 period were included into this study (Table 1). One hundred and twenty-two (76.3\%) patients were younger than 18 years of age. The majority of pediatric patients (59.5\%) were stratified to NOPHO 2008 standard risk treatment arm. In contrast, more than half of the adult patients were stratified either to intermediate (44.7\%) or high risk/high risk SCT disease (29.0\%). 
Table 1

Clinical characteristics of B-ALL patients.

\begin{tabular}{|c|c|c|c|c|}
\hline \multicolumn{5}{|l|}{ Age groups } \\
\hline & $1-17$ yo & 18-65 yo & All & $\mathrm{p}$-Value \\
\hline Number of patients & $122(76.3 \%)$ & $38(23.7 \%)$ & $160(100 \%)$ & \\
\hline Median age (range) & $4(1-17)$ & $32(18-65)$ & $5(1-65)$ & \\
\hline \multicolumn{5}{|l|}{ Sex: } \\
\hline Male & $69(56.6 \%)$ & $15(39.5 \%)$ & $84(52.5 \%)$ & \multirow[t]{2}{*}{0.093} \\
\hline Female & $53(43.4 \%)$ & $23(60.5 \%)$ & $76(47.5 \%)$ & \\
\hline \multicolumn{5}{|l|}{ Risk group: } \\
\hline SR & $72(59.5 \%)$ & $7(18.4 \%)$ & 79 (49.7\%) & \multirow[t]{6}{*}{$<0.001$} \\
\hline IR & 38 (31.4\%) & $17(44.7 \%)$ & 55 (34.6\%) & \\
\hline HR & $5(4.1 \%)$ & $6(15.8 \%)$ & $11(6.9 \%)$ & \\
\hline HR-SCT & $3(2.5 \%)$ & $5(13.2 \%)$ & $8(5 \%)$ & \\
\hline Induction failure & $3(2.5 \%)$ & $3(7.9 \%)$ & $6(3.8 \%)$ & \\
\hline Not risk grouped & 1 & 0 & 1 & \\
\hline \multicolumn{5}{|l|}{ Induction: } \\
\hline Prednisolone & $113(92.6 \%)$ & 30 (78.9\%) & $143(89.4 \%)$ & \multirow[t]{2}{*}{0.030} \\
\hline Dexamethasone & $9(7.4 \%)$ & $8(21.1 \%)$ & $17(10.6 \%)$ & \\
\hline \multicolumn{5}{|l|}{ WBC (x 109/l): } \\
\hline$<100$ & $113(92.6 \%)$ & $30(78.9 \%)$ & $143(89.4 \%)$ & \multirow[t]{2}{*}{0.030} \\
\hline$\geq 100$ & $9(7.4 \%)$ & $8(21.1 \%)$ & $17(10.6 \%)$ & \\
\hline WBC median (range) & $14(1-641)$ & $10.5(0.9-481.9)$ & $13.5(0.9-641)$ & 0.672 \\
\hline $\mathrm{Hgb}(\mathrm{g} / \mathrm{l})$ median (range) & $83(24-140)$ & $90.5(52-142)$ & $84(24-142)$ & 0.117 \\
\hline Platelets median (range) & $62(0-457)$ & $37(5-320)$ & $54.5(0-457)$ & 0.075 \\
\hline \multicolumn{5}{|l|}{ CNS Status: } \\
\hline CNS1 & $104(85.2 \%)$ & 33 (86.8\%) & 137 (85.6\%) & \multirow[t]{3}{*}{0.281} \\
\hline CNS2 & $14(11.5 \%)$ & $2(5.3 \%)$ & $16(10 \%)$ & \\
\hline CNS3 & $4(3.3 \%)$ & $3(7.9 \%)$ & $7(4.4 \%)$ & \\
\hline
\end{tabular}

\section{Genetic analysis}

Gene fusion analysis

Routine karyotyping, FISH and standard PCR methods were used to identify canonical B-ALL genomic alterations at diagnosis. In order to detect non-canonical B-ALL genomic lesions, we performed RNA-Seq and FISH (CRLF2 break) analysis in B-ALL cases lacking canonical gene fusions or $\operatorname{dic}(9: 20) /$ iAMP21 aberrations.

In total, 99/160 (61.9\%) cases harbored at least one canonical B-ALL genomic alteration (Table 2, Additional file 1: Fig. S1). High hyperdiploidy was identified in 35/160 (21.9\%) patients. Low hypodiploidy was present in 5/160 (3.1\%) cases. ETV6-RUNX1 fusions were detected in $34 / 160(21.3 \%)$ cases and were more common among children than adults (33 children vs. 1 adult, $p=0.001)$. In contrast, KMT2A gene rearrangements were detected in 11/160 (6.9\%) B-ALL cases (4 children vs. 7 adults). Importantly, RNA-Seq analysis 
identified two KMT2A gene rearrangements (del(11q23)/KMT2A-CBL, del(11q23)/KMT2A-ATP5L) that had been missed by FISH. iAMP21 aberration was exclusive to the pediatric group $(n=3,1.9 \%)$ while dic $(9 ; 20)$ was present in $1 / 160(0.6 \%)$ adult patient.

Table 2

Genomic subgroups of canonical and non-canonical B-ALL alterations in study patients.

\begin{tabular}{|c|c|c|c|c|}
\hline & Genomic alterations & $\begin{array}{l}\text { Pediatric group }(n= \\
122)\end{array}$ & $\begin{array}{l}\text { Adult group }(n= \\
38)\end{array}$ & $\begin{array}{l}\text { Total cohort }(n= \\
160)\end{array}$ \\
\hline \multirow[t]{8}{*}{ Canonical alterations } & ETV6-RUNX1 & $33(27.1 \%)$ & $1(2.6 \%)$ & $34(21.3 \%)$ \\
\hline & TCF3-PBX1 & $7(5.7 \%)$ & $3(7.9 \%)$ & $10(6.3 \%)$ \\
\hline & KMT2A gene rearrangements & $4(3.3 \%)$ & $7(18.4 \%)$ & $11(6.9 \%)$ \\
\hline & iAMP21 & $3(2.5 \%)$ & 0 & $3(1.9 \%)$ \\
\hline & $\operatorname{dic}(9 ; 20)$ & 0 & $1(2.6 \%)$ & $1(0.6 \%)$ \\
\hline & High hyperdiploidy & $32(26.2 \%)$ & $3(7.9 \%)$ & $35(21.9 \%)$ \\
\hline & Low hypodiploidy & $2(1.6 \%)$ & $3(7.9 \%)$ & $5(3.1 \%)$ \\
\hline & No canonical alterations & $41(33.6 \%)$ & $20(52.7 \%)$ & $61(38.1 \%)$ \\
\hline \multirow{6}{*}{$\begin{array}{l}\text { Non-canonical } \\
\text { alterations* }\end{array}$} & $\mathrm{ABL}$-class fusions & 0 & $3(7.9 \%)$ & $3(1.9 \%)$ \\
\hline & JAK-STAT pathway fusions & $2(1.6 \%)$ & $2(5.3 \%)$ & $4(2.5 \%)$ \\
\hline & Other fusions ${ }^{\star \star}$ & $10(8.2 \%)$ & 0 & $10(6.3 \%)$ \\
\hline & $\begin{array}{l}\text { JAK-STAT pathway } \\
\text { mutations }\end{array}$ & $6(4.9 \%)$ & $4(10.5 \%)$ & $10(6.3 \%)$ \\
\hline & Ras pathway mutations & $39(32.0 \%)$ & $14(36.8 \%)$ & $53(33.1 \%)$ \\
\hline & FLT3-TKD mutations & $7(5.7 \%)$ & $1(2.6 \%)$ & $8(5.0 \%)$ \\
\hline
\end{tabular}

After the exclusion of two patients with KMT2A gene rearrangements identified by RNA-Seq, remaining cases without canonical B-ALL gene fusions and cases with high hyperdiploidy or low hypodiploidy were selected for RNA-Seq and CRLF2 gene break FISH analysis to identify additional kinase and cytokine receptor activating lesions (Additional file 1: Fig. S1).

In-frame fusions of ABL-class genes were detected in 3/160 (1.9\%) patients (Table 2; Fig. 1). One case had t(9;12)/ETV6-ABL 1 fusion previously reported in both lymphoid and myeloid leukemias [21]. The remaining two cases harbored $\mathrm{t}(1 ; 7) / Z C 3 H A V 1-A B L 2$ and $\mathrm{t}(5 ; 5)$ / EBF1-PDGFRB fusions. ABL-class fusions were exclusive to adults $(\mathrm{p}=0.030)$.

JAK-STAT pathway fusions were identified in 4/160 (2.5\%) cases. ABL-class and JAK-STAT pathway fusions were mutually exclusive. RNA-seq identified $\mathrm{t}(9 ; 22) / B C R$-JAK2 fusion in one pediatric patient. FISH analysis revealed three cases with $\mathrm{t}(\mathrm{Y} ; 14)(\mathrm{X} ; 14) /$ IGH-CRLF2 gene fusion, of which two were adults. A case positive for BCR-JAK2 fusion also showed high hyperdiploidy which further confirms that patients with high hyperdiploidy can harbor additional JAK-STAT pathway fusions. Both adult cases with IGH-CRLF2 fusions had additional gene mutations. One IGH-CRLF2-positive case harbored FLT3-TKD ${ }^{\mathrm{D} 835 \mathrm{Y}}$ and $N R A S^{\mathrm{G} 13 \mathrm{R}}$ gene mutations while another case had $C R L F 2^{F 232 C}$ gene mutation. RNA-seq and FISH analysis detected no P2RY8-CRLF2 fusions in our study patients. SNP Array analysis was available for $81 / 101(80.2 \%)$ of the sequenced B-ALL patients. No deletions of PAR1 region were identified in any of the cases confirming the absence of $P 2 R Y 8-C R L F 2$ fusion.

We identified other gene fusions in 10/160 (6.3\%) pediatric B-ALL cases. Five cases had PAX5 gene rearrangements: $\mathrm{t}(9 ; 18) / P A X 5$ GREB1L, $\mathrm{t}(9 ; 20) / P A X 5-N C O A 5$, dic(9;12)/ PAX5-ETV6, dic(3;9)/PAX5-FOXP1 and dic(9;20)/PAX5-NOL4L. One case with PAX5-GREB1L fusion had additional $J A K 7^{\mathrm{F} 838 \mathrm{~V}}$ mutation, while in other two $P A X 5$-rearranged cases $K R A S^{\mathrm{G} 12 \mathrm{~V}}$ and $N R A S^{\mathrm{G} 12 \mathrm{C}}$ gene mutations were identified. Three cases had fusions involving ZNF384 gene (EP300-ZNF384, $\mathrm{n}=2 ;$;CF3-ZNF384, $\mathrm{n}=1$ ) of which TCF3-ZNF384 positive 
case had additional $N R A S^{G 13 R}$ mutation. Though ETV6-RUNX1 is the most common alteration in childhood B-ALL, data analysis revealed a novel fusion of ETV6 and RUNX2 genes in one pediatric patient while another patient harbored $\mathrm{t}(7 ; 15) / C U X 1-N U M T 1$ fusion.

Gene mutation analysis

Gene mutation analysis of RNA-Seq data revealed other JAK-STAT pathway mutations in a total of 9/160 (5.6\%) cases: JAK1 $(n=2)$, JAK2 $(\mathrm{n}=7)$, CRLF2 ( $\mathrm{n}=1$ ) (Table 2; Fig. 1; Additional file 1: Table S2). One case had both JAK1 and JAK2 gene mutations in the same sample. In all cases, protein kinase 1 and kinase 2 domains of JAK1 and JAK2 genes were affected. Four JAK2-mutated cases were comutated with Ras pathway genes $(K R A S \mathrm{n}=2 ; N R A S \mathrm{n}=1$; PTPN11 $\mathrm{n}=1)$.

A total of fifty-three Ras pathway gene point mutations were detected in 48/160 (30\%) B-ALL cases (Table 2; Fig. 1; Additional file 1: Table S2). NRAS gene mutations were the most common $(\mathrm{n}=29)$ while the incidence of $K R A S(\mathrm{n}=17)$ and PTPN11 $(\mathrm{n}=7)$ gene mutations was lower. One case had mutations in NRAS and PTPN11 genes while another case had two different NRAS gene mutations (G12S and G12A) in the same sample. Two other cases had both KRAS and NRAS gene mutations in the same sample. Ras pathway mutations were detected in 16/35 (45.7\%) high hyperdyploid and $2 / 5$ (40\%) low hypodiploidy cases.

FLT3-TKD activating mutations of codons D835 $(n=5)$ and $1836(n=3)$ were found in 8/160 (5\%) cases. Most of the FLT3-TKD positive cases (75\%) were present with Ras pathway gene mutations. Other FLT3 gene kinase domain point mutations were present in $5(3.1 \%)$ patients (Fig. 1).

Other gene variants were identified in 23 (14.4\%) B-ALL patients while 14 (8.8\%) patients had no specific B-ALL gene fusions/variants detected by RNA-Seq.

\section{Clinical outcome of patients with ABL-class or JAK-STAT fusions}

Five of 38 adults (13.2\%) and only two of 122 children (1.6\%) were positive for either ABL-class or JAK-STAT pathway fusions (AJSpositive group) (Table 3). Overall, both EFS and OS were worse in AJS-positive group vs AJS-negative $(n=153)($ Fig. 2A). 
Table 3

Genetic features and clinical outcome of ABL-class or JAK-STAT pathway fusion (AJS)-positive patients.

\begin{tabular}{|c|c|c|c|c|c|c|c|c|c|c|c|c|}
\hline $\begin{array}{l}\text { Case } \\
\text { no. }\end{array}$ & Gender & Age & $\begin{array}{l}\text { In-frame } \\
\text { gene } \\
\text { fusion }\end{array}$ & WBC & $\begin{array}{l}\text { DEX / } \\
\text { PREDNI }\end{array}$ & $\begin{array}{l}\text { MRD } \\
\text { D15 }\end{array}$ & $\begin{array}{l}\text { MRD } \\
\text { D29 }\end{array}$ & $\begin{array}{l}\text { MRD } \\
\text { D79 }\end{array}$ & $\begin{array}{l}\text { Risk } \\
\text { Group }\end{array}$ & $\begin{array}{l}\text { allosct } \\
(\mathrm{Y} / \mathrm{N})\end{array}$ & Event(Y/N) & Comment \\
\hline $\begin{array}{l}\text { Case } \\
1\end{array}$ & $M$ & 55 & $\begin{array}{l}\text { ETV6- } \\
A B L 1\end{array}$ & 270 & DEX & - & - & - & - & $\mathrm{N}$ & Y & $\begin{array}{l}\text { Induction } \\
\text { death }\end{array}$ \\
\hline $\begin{array}{l}\text { Case } \\
2\end{array}$ & $\mathrm{~F}$ & 24 & $\begin{array}{l}\text { ZC3HAV1- } \\
\text { ABL2 }\end{array}$ & 72 & PREDNI & $30.5 \%$ & $6.5 \%$ & $0.01 \%$ & IR & Y & Y & $\begin{array}{l}\text { Death of } \\
\text { sepsis } \\
\text { after } \\
\text { alloSCT } \\
\text { in CR1 }\end{array}$ \\
\hline $\begin{array}{l}\text { Case } \\
3\end{array}$ & $M$ & 18 & $\begin{array}{l}\text { EBF1- } \\
\text { PDGFRB }\end{array}$ & 258 & DEX & $45.3 \%$ & $\begin{array}{l}0.93 \% \\
\text { (POST } \\
\text { A1) }\end{array}$ & $\begin{array}{l}0.7 \% \\
\text { (POST } \\
\text { B1) }\end{array}$ & $\begin{array}{l}\text { HR- } \\
\text { SCT }\end{array}$ & Y & Y & $\begin{array}{l}\text { Relapse } \\
\text { after } \\
\text { alloSCT } \\
\text { and } \\
\text { death }\end{array}$ \\
\hline $\begin{array}{l}\text { Case } \\
4\end{array}$ & $\mathrm{~F}$ & 32 & $\begin{array}{l}\text { IGH- } \\
\text { CRLF2 }\end{array}$ & 4 & PREDNI & $11.6 \%$ & $20.3 \%$ & $3.4 \%$ & $\begin{array}{l}\text { HR- } \\
\text { SCT }\end{array}$ & Y & Y & $\begin{array}{l}\text { Relapse } \\
\text { after } \\
\text { alloSCT } \\
\text { and alive } \\
\text { in CR2 }\end{array}$ \\
\hline $\begin{array}{l}\text { Case } \\
5\end{array}$ & $M$ & 48 & $\begin{array}{l}\text { IGH- } \\
\text { CRLF2 }\end{array}$ & 104 & DEX & $44.3 \%$ & $8 \%$ & $1.65 \%$ & $\begin{array}{l}\text { HR- } \\
\text { SCT }\end{array}$ & $Y$ & $\mathrm{~N}$ & $\begin{array}{l}\text { Alive } \\
\text { after } \\
\text { alloSCT } \\
\text { in CR1 }\end{array}$ \\
\hline $\begin{array}{l}\text { Case } \\
6\end{array}$ & $\mathrm{~F}$ & 13 & $\begin{array}{l}\text { IGH- } \\
\text { CRLF2 }\end{array}$ & 35 & PREDNI & $0.22 \%$ & $<0.1 \%$ & $0.3 \%$ & $\begin{array}{l}\text { HR- } \\
\text { SCT }\end{array}$ & Y & $\mathrm{N}$ & $\begin{array}{l}\text { Alive } \\
\text { after } \\
\text { alloSCT } \\
\text { in CR1 }\end{array}$ \\
\hline $\begin{array}{l}\text { Case } \\
7\end{array}$ & $M$ & 6 & $B C R-J A K 2$ & 5 & PREDNI & $1.8 \%$ & $0.33 \%$ & $<0.1 \%$ & IR & $\mathrm{N}$ & $\mathrm{N}$ & $\begin{array}{l}\text { Alive in } \\
\text { CR1 }\end{array}$ \\
\hline
\end{tabular}

We further compared the outcome of AJS positive $(n=5)$ vs. AJS negative $(n=33)$ B-ALL cases in adults since the number of AJSpositive pediatric cases was too small for detailed analysis. Four AJS-positive adult patients were evaluable for residual disease on induction day 15 (one patient died during induction). All four AJS-positive patients (100\%) had $\geq 5 \%$ blasts on day 15 compared to 9 $(29 \%)$ AJS-negative patients $(p=0.019)$ (Table 4). After day 15 , one patient was assigned to block treatment therefore three patients had MRD data available on day 29. MRD levels on days 29 and 79 were higher in AJS-positive group compared to AJS-negative group. As a result of poor MRD response, more AJS-positive than AJS-negative adult patients had induction failure or were assigned to HR/HR-SCT group (4 (80.0\%) vs $10(30.3 \%)$, respectively, $\mathrm{p}=0.052)$. 
Table 4

Minimal residual disease of AJS-positive vs. AJS-negative adult patients on days 15, 29 and 79.

\begin{tabular}{|c|c|c|c|}
\hline MRD & AJS-positive $(n=5)$ & AJS-negative $(n=33)$ & p-Value (Chi-Square) \\
\hline D15 <5\% & $0(0 \%)$ & $22(71 \%)$ & 0.019 \\
\hline$\geq 5 \%$ & $4(100 \%) 1$ missing & 9 (29\%) 2 missing & \\
\hline D29 $<5 \%$ & $0(0 \%)$ & $30(96.8 \%)$ & $<0.001$ \\
\hline$\geq 5 \%$ & $3(100 \%) 2$ missing & $1(3.2 \%) 2$ missing & \\
\hline D29 <0.1\% & $0(0 \%)$ & $21(67.7 \%)$ & 0.011 \\
\hline$\geq 0.1 \%$ & $3(100 \%) 2$ missing & $10(32.3 \%) 2$ missing & \\
\hline D79 $<0.1 \%$ & $2(50 \%)$ & $26(89.7 \%)$ & 0.120 \\
\hline$\geq 0.1 \%$ & 2 (50\%) 1 missing & $3(10.3 \%) 4$ missing & \\
\hline
\end{tabular}

The median observation time in adults was 39 months. The 75th percentile EFS was 5 vs. 35 months $(p=0.009)$ and OS was 14 vs. 36 months $(p=0.098)$ in AJS-positive vs. AJS-negative adults, respectively (Fig. 2B). Since all patients were risk assigned and treated according to the NOPHO ALL-2008 protocol, we performed a multivariate analysis of risk-group assignment and AJS-positivity on outcome in adults. In multivariate analysis, having ABL-class or JAK-STAT pathway fusions was an independent risk factor for worse EFS $(p=0.046)($ Table 5).

Table 5

Multivariate analysis of EFS and OS of MRD-assigned risk and AJS-positive groups in adults.

\begin{tabular}{|lllll|}
\hline Risk Groups & EFS & & OS & p-Values \\
\hline & Hazard Ratio & p-Values & Hazard Ratio & - \\
\hline SR & reference & - & reference & 0.468 \\
\hline IR & $0.885(0.220-3.570)$ & 0.846 & $2.219(0.257-19.136)$ & 0.720 \\
\hline HR + HR-SCT & $0.753(0.146-3.875)$ & 0.734 & $1.568(0.134-18.298)$ & 0.278 \\
\hline AJS-positive & $5.545(1.057-29.090)$ & 0.046 & $2.783(0.436-17.881)$ & \\
\hline $\begin{array}{l}\text { SR, standard risk; IR, intermediate risk; HR, high risk; HR-SCT, high risk-stem cell transplant groups; AJS, ABL-class or JAK-STAT } \\
\text { pathway fusions; EFS, event-free survival; OS, overall survival; MRD, minimal residual disease. }\end{array}$ & \\
\hline
\end{tabular}

\section{Discussion}

We present the first Baltic European population-based study of genomic alterations among pediatric and adult BCR-ABL 1-negative B-ALL patients. All patients were uniformly treated according to NOPHO ALL-2008 protocol with risk stratification according to both the canonical B-ALL genomic lesions and minimal residual disease. We selected targeted RNA-Seq and FISH methods for the detection of known and novel gene rearrangements of ABL-class and JAK-STAT pathway genes and other kinase alterations.

In our study, ABL-class fusions were identified in 3/160 (1.9\%) B-ALL cases. All positive cases were adults (3/38, 7.9\%) (Table 2). In comparison, in the Dutch/German cohort 9 of 153 (5.9\%) pediatric B-ALL patients without canonical B-ALL alterations harbored ABL-class fusions [11]. Another European study by Zaliova et al. revealed only 1/75 (1.3\%) pediatric B-ALL case with ABL 1 gene rearrangement [22] while ABL-class fusions were present in 40/1389 (2.9\%) high-risk pediatric B-ALL patients in an US Children's Oncology Group study [10]. Heatley at el. performed targeted RNA-Seq in 63 adolescent/young adults (16-39 yo) and 63 adults (40-88 yo) with BCR-ALB1-negative B-ALL [23]. ABL-class fusions were found in 4/126 (3.2\%) of these B-ALL cases. A study by Garrido et al. used FISH method to analyze 39 adult B-ALL patients negative for BCR-ABL 1 and $K M T 2 A$ gene rearrangements and identified $3 / 39(7.7 \%)$ cases with ABL-class fusions 
$(A B L 1 \mathrm{n}=2 ;$ CSF1R $\mathrm{n}=1)$ [24]. In a similar study from UKALL14 clinical trial, ABL-class abnormalities were present in 6/648 (< 1\%) $\mathrm{B}$-ALL patients [25]. The incidence of ABL-class fusions of $7.9 \%$ in our adult B-ALL patients was largely in line with published adult studies, however we did not detect ABL-class fusions in our pediatric B-ALL patients.

We identified JAK-STAT pathway fusions in 4/160 (2.5\%) B-ALL cases. JAK-STAT pathway fusions occur in approximately 3 - 5\% of childhood and in up to $15 \%$ of adult B-ALL [3]. A study by Heatley et al. showed the incidence rate in adults of 15.9\% [23], however another study revealed that only $5.1 \%$ of adult B-ALL had JAK-STAT pathway fusions [25]. Similarly, our data indicate lower frequency of JAKSTAT pathway fusions in both adult and pediatric Lithuanian B-ALL patients.

Overall, the frequency of $C R L F 2$ rearrangements in B-ALL is approximately $5 \%$ and the rate gets higher in cases without canonical B-ALL alterations (10-30\%) and in patients with Down syndrome (>50\%) [22, 23, 26-27, 42]. In our study, IGH-CRLF2 fusions were present in 3/160 (1.9\%) B-ALL cases. Notably, we did not detect any P2RY8-CRLF2 gene fusions in our cohort by either RNA-Seq or FISH (CRLF2 Break Probe) methods. In comparison, a Swedish study identified CRLF2 gene rearrangements in 16 of 189 (8.5\%) pediatric $B C R-A B L-$ negative B-ALL patients, of which P2RY8-CRLF2 fusion was the most common (12/16, 75\%) [42]. P2RY8-CRLF2 gene fusion is the result of deletion of PAR1 region in either $\mathrm{X}$ or $\mathrm{Y}$ chromosomes. To further confirm the absence of $P 2 R Y 8-C R L F 2$ fusion, we used SNP Array data of $81 / 101(80.2 \%)$ sequenced patients and did not detect any deletions in the corresponding PAR1 region. In addition, another study has shown that $P 2 R Y 8-C R L F 2$ gene fusion can be identified using the RNA-Seq method and analysis algorithm similar to ours [41] making it unlikely that $P 2 R Y 8-C R L F 2$ fusion was missed due to technical reasons in our study patients. $C R L F 2$ gene rearrangements are common in populations with Hispanic ancestry and are associated with increased risk of relapse in both children and adults [13, 29, 30]. Population differences may explain a lower frequency of IGHCRLF2 and the absence of P2RY8-CRLF2 gene fusions in our cohort. In other B-ALL studies, approximately half of CRLF2-rearranged patients also harbored additional JAK1 or JAK2 gene mutations [10], however our positive cases had no such mutations. Of note, one case had FLT3-TKD ${ }^{\mathrm{D} 835 \mathrm{Y}}$ and NRAS ${ }^{\mathrm{G} 13 \mathrm{R}}$ gene mutations and another case was positive for a $C R L F 2^{\mathrm{F} 232 \mathrm{C}}$ activating mutation. $C R L F 2^{\mathrm{F} 232 \mathrm{C}}$ gene mutation is known to promote constitutive dimerization and cytokineindependent growth which results in gene overexpression in a similar manner as with CRLF2 gene rearrangement [31].

Other gene fusions were found in 10 (6.3\%) patients and were exclusive to the pediatric group (Fig. 1). RNA-Seq data were used for gene mutation analysis with a caveat that only expressed sequence variants of targeted genes could be evaluated. In most cases, the coverage of particular mutations calculated from RNA-Seq data was inadequate to accurately determine their frequencies in the sample, therefore, we did not evaluate mutation-based clonality/subclonality. In our study, other gene fusions and gene point mutations had no statistical significance on either EFS or OS among all age groups.

RNA-Seq analysis revealed two adult B-ALL cases with $K M T 2 A$ gene rearrangements that had been missed by FISH analysis at diagnosis. Both samples had blast counts of $>90 \%$. We re-run FISH analysis, however, the secondary results were also negative. Notably, both fusions were formed as a result of the aberrations of the 11q23 chromosome region. The close proximity of fused genes and relatively small size of chromosome deletions could have potentially caused false negative FISH results. Patients with KMT2A gene rearrangements have lower survival rates and generally require therapy intensification in first remission [2]. KMT2A-ATP5L fusion was also recently described as an unfavorable prognostic marker in young adults with Ph-like ALL [32]. Our findings demonstrate the additive advantage of RNA-Seq diagnostic method in B-ALL patients who are negative for canonical B-ALL fusions by FISH analysis.

Ph-like B-ALL has been associated with worse outcome in several studies [14, 15, 33]. Roberts with colleagues [17] performed a gene expression profiling of 344 B-ALL patients and found that 40/344 (11.6\%) children with Ph-like B-ALL had higher MRD values on both day 19 and at the end of induction compared to non-Ph-like B-ALL patients. However, the EFS and OS was not different in both groups due to MRD-risk directed treatment of the Total Therapy XV protocol [17]. Ph-like B-ALL adult patients were noted to have a lower probability of achieving molecular complete remission, had a lower probability of continuous complete remission and OS in GMALL studies 06/99 and 07/03 [16]. Only limited MRD-directed treatment was applied in GMALL 07/03 study with persistently MRD positive standard-risk patients having an option of SCT. ${ }^{34}$ In another study of patients entering different study protocols, Ph-like B-ALL was associated with worse outcome in young but not older adults [35]. Likewise, lower EFS and OS was noted in adult Ph-like B-ALL patients in MD Anderson studies [15]. In a CALGB10403 study of young (18-40 year-old) adults treated according to a pediatric high-risk non-MRD directed protocol, patients with Ph-like fusions had a 3-year EFS of $42 \%$ in contrast to $69 \%$ for those without these fusions and patients with Ph-like B-ALL signature were less likely to have negative MRD compared to patients without the signature [36].

There are several important differences in our study. First, all patients were treated according to MRD-risk directed NOPHO 2008 protocol and patients with poor MRD response were assigned to therapy intensification with or without allogeneic SCT [2]. Second, we studied the ABL-class or JAK-STAT pathway fusion-positive patients only who mostly but not exclusively cluster within Ph-like group [14].

Page 10/15 
Nevertheless, we found that patients with ABL-class or JAK-STAT pathway fusions (AJS-positive group) were more likely to have poor MRD response compared to patients without these fusions (AJS-negative group) and thus were more likely to be assigned to higher risk groups resulting in therapy intensification. In our study, AJS-positive adult patients had lower EFS and a trend for lower OS. In multivariate analysis, AJS-positivity was a risk factor for worse EFS $(p=0.046)$ but not OS $(p=0.278)$ in adults (Table 5$)$.

Our results are supported by pediatric B-ALL studies focusing on cytogenetic analysis of ABL-class and/or JAK-STAT pathway fusions. A study of UKALL2003 trial patients by O'Connor et al. [38] examined pediatric ALL patients with induction failure (leukemic blasts $>5 \%$ and/or MRD $\geq 5 \%$ ) revealing a high rate of ABL-class $(>30 \%)$ or CRLF2 $(11 \%)$ rearrangements. Similarly, in a study by Cario et al., 46 pediatric B-ALL patients with ABL-class fusions treated according to AIEOP-BFM protocols showed high rates of MRD $(\geq 5 \times 10-4)$ positivity (71.4\% and $51.2 \%$ after induction and consolidation, respectively) [40]. We observed similar poor MRD responses in our ABLclass / JAK-STAT fusion-positive adult patients despite MRD directed treatment. Importantly, ABL-class positive patients who received a TKI as part of their UKALL2011 protocol first remission treatment showed a lower relapse rate [39].

Our study has limitations. Though the NOPHO 2008 protocol included children and adults from Nordic, Baltic (Lithuania and Estonia) countries and Iceland, we had access to and studied Lithuanian patients only. The number of ABL-class or JAK-STAT pathway fusionpositive patients was low and few events occurring by chance could have significantly affected the clinical outcome. As already mentioned, our results are not directly comparable to the previous studies of Ph-like B-ALL. Nevertheless, the results of our study are clinically relevant. We report the results of a relatively large and homogenous group of pediatric and adult patients coming from the Baltic part of Europe and show that the incidence of ABL-class or JAK-STAT pathway fusions in this geographic area is lower compared to the US or other European regions [10,11, 14, 25, 38, 39, 42]. Our results suggest that AJS-positive group patients have poor MRD response and MRD-risk directed treatment may not be sufficient to overcome the adverse effect of AJS-positivity in adults. Importantly, clinical studies have shown that specific ABL-class fusions can be successfully targeted with tyrosine kinase inhibitors such as dasatinib or imatinib even in refractory B-ALL $[7,8,37,39,40]$. Arguably, the detection of ABL-class or JAK-STAT pathway fusions could be reserved for poor B-ALL MRD responders. This could have significant financial and logistical implications since only a limited number of B-ALL patients will need to be tested for ABL-class or JAK-STAT pathway fusions.

\section{Conclusions}

ABL-class and JAK-STAT pathway fusions are uncommon in the population-based cohort of Lithuanian BCR-ABL 1-negative B-ALL patients. Specifically, P2RY8-CRLF2 gene fusion was not detected using three different genetic interrogation methods. The poor MRD response and poor clinical outcome in patients harboring either ABL-class or JAK-STAT pathway fusions should be confirmed in future prospective studies.

\section{Abbreviations}

ALL: acute lymphoblastic leukemia; EFS: event-free survival; FISH: fluorescence in situ hybridization; GMALL: German multicenter study group for adult ALL; HR: high risk; IR: intermediate risk; JAK-STAT: Janus kinase-signal transducers and activators of transcription; MRD: minimal residual disease; NOPHO: Nordic Society for Pediatric Hematology and Oncology; OS: overall survival; PCR: polymerase chain reaction; SCT: stem cell transplant; SNP: single nucleotide polymorphism; SR: standard risk; TKI: tyrosine kinase inhibitor;

\section{Declarations}

\section{Ethics approval and consent to participate}

The study was conducted in accordance with the Declaration of Helsinki, and the protocol was approved by Vilnius Regional Bioethics Committee. The patients provided written informed consent. The waiver for obtaining written informed consent from patients who could not be reached despite best efforts had been approved by Vilnius Regional Bioethics Committee according to national regulations.

\section{Consent for publication}

Not applicable.

\section{Availability of data and materials}

The datasets used during the current study are available from the corresponding author on reasonable request. 


\section{Competing interests}

The authors declare that they have no competing interests

\section{Funding}

Not applicable.

\section{Authors' contributions}

RN performed the experiments and carried out bioinformatic analysis; VD performed the experiments; OM carried out statistical analysis; RS and GV were involved in collecting patient data; VD, OM, RS, EG, MS, JR were involved in manuscript editing. RN, LG were major contributors to study design and manuscript writing; LG supervised the project. All authors have read and approved the manuscript.

\section{Acknowledgements}

The authors would like to thank the patients and their families for contributing to this study.

\section{Author details}

${ }^{1}$ Hematology, Oncology and Transfusion Medicine Center, Vilnius University Hospital Santaros Klinikos, Vilnius, Lithuania. ${ }^{2}$ Department of Experimental, Preventive and Clinical Medicine, Institute for Innovative Medicine, Vilnius, Lithuania. ${ }^{3}$ Institute of Clinical Medicine, Vilnius University, Vilnius, Lithuania. ${ }^{4}$ Center for Pediatric Oncology and Hematology, Vilnius University Hospital Santaros Klinikos, Vilnius, Lithuania

\section{References}

1. Mullighan CG. The molecular genetic makeup of acute lymphoblastic leukemia. Hematology Am Soc Hematol Educ Program. 2012;2012:389-96.

2. Toft N, Birgens H, Abrahamsson J, Griškevičius L, Hallböök H, Heyman M, et al. Results of NOPHO ALL2008 treatment for patients aged 1-45 years with acute lymphoblastic leukemia. Leukemia. 2018;32(3):606-15.

3. Moorman AV. New and emerging prognostic and predictive genetic biomarkers in B-cell precursor acute lymphoblastic leukemia. Haematologica. 2016;101(4):407-16.

4. Den Boer ML, van Slegtenhorst M, De Menezes RX, Cheok MH, Buijs-Gladdines JG, Peters ST, et al. A subtype of childhood acute lymphoblastic leukaemia with poor treatment outcome: a genome-wide classification study. Lancet Oncol. 2009;10(2):125-34.

5. Mullighan CG, Su X, Zhang J, Radtke I, Phillips LA, Miller CB, et al. Deletion of IKZF1 and prognosis in acute lymphoblastic leukemia. N Engl J Med. 2009;360(5):470-80.

6. Roberts KG, Morin RD, Zhang J, Hirst M, Zhao Y, Su X, et al. Genetic alterations activating kinase and cytokine receptor signaling in high-risk acute lymphoblastic leukemia. Cancer Cell. 2012;22(2):153-66.

7. Weston BW, Hayden MA, Roberts KG, Bowyer S, Hsu J, Fedoriw G, et al. Tyrosine kinase inhibitor therapy induces remission in a patient with refractory EBF1-PDGFRB-positive acute lymphoblastic leukemia. J Clin Oncol. 2013;31(25):e413-6.

8. Roberts KG, Yang YL, Payne-Turner D, Lin W, Files JK, Dickerson K, et al. Oncogenic role and therapeutic targeting of ABL-class and JAK-STAT activating kinase alterations in Ph-like ALL. Blood Adv. 2017;1(20):1657-71.

9. Ding YY, Stern JW, Jubelirer TF, Wertheim GB, Lin F, Chang F, et al. Clinical efficacy of ruxolitinib and chemotherapy in a child with Philadelphia chromosome-like acute lymphoblastic leukemia with GOLGA5-JAK2 fusion and induction failure. Haematologica. 2018;103(9):e427-31.

10. Reshmi SC, Harvey RC, Roberts KG, Stonerock E, Smith A, Jenkins H, et al. Targetable kinase gene fusions in high-risk B-ALL: a study from the Children's Oncology Group. Blood. 2017;129(25):3352-61.

11. Boer JM, Steeghs EM, Marchante JR, Boeree A, Beaudoin JJ, Beverloo HB, et al. Tyrosine kinase fusion genes in pediatric BCR-ABL1like acute lymphoblastic leukemia. Oncotarget. 2017;8(3):4618-28.

12. Kotb A, El Fakih R, Hanbali A, Hawsawi Y, Alfraih F, Hashmi S, Aljurf M. Philadelphia-like acute lymphoblastic leukemia: diagnostic dilemma and management perspectives. Exp Hematol. 2018;67:1-9. 
13. Chiaretti S, Brugnoletti F, Messina M, Paoloni F, Fedullo AL, Piciocchi A, et al. CRLF2 overexpression identifies an unfavourable subgroup of adult B-cell precursor acute lymphoblastic leukemia lacking recurrent genetic abnormalities. Leuk Res. 2016;41:36-42.

14. Roberts KG, Li Y, Payne-Turner D, Harvey RC, Yang YL, Pei D, et al. Targetable kinase-activating lesions in Ph-like acute lymphoblastic leukemia. N Engl J Med. 2014;371(11):1005-15.

15. Jain N, Roberts KG, Jabbour E, Patel K, Eterovic AK, Chen K, et al. Ph-like acute lymphoblastic leukemia: a high-risk subtype in adults. Blood. 2017;129(5):572-81.

16. Herold T, Schneider S, Metzeler KH, Neumann M, Hartmann L, Roberts KG, et al. Adults with Philadelphia chromosome-like acute lymphoblastic leukemia frequently have IGH-CRLF2 and JAK2 mutations, persistence of minimal residual disease and poor prognosis. Haematologica. 2017;102(1):130-8.

17. Roberts KG, Pei D, Campana D, Payne-Turner D, Li Y, Cheng C, et al. Outcomes of children with BCR-ABL1-like acute lymphoblastic leukemia treated with risk-directed therapy based on the levels of minimal residual disease. J Clin Oncol. 2014;32(27):3012-20.

18. Pui CH, Pei D, Raimondi SC, Coustan-Smith E, Jeha S, Cheng C, et al. Clinical impact of minimal residual disease in children with different subtypes of acute lymphoblastic leukemia treated with Response-Adapted therapy. Leukemia. 2017;31(2):333-9.

19. Holmfeldt L, Wei L, Diaz-Flores E, Walsh M, Zhang J, Ding L, et al. The Genomic Landscape Of Hypodiploid Acute Lymphoblastic Leukemia. Nat Genet. 2013;45(3):242-52.

20. Paulsson K, Lilljebjörn H, Biloglav A, Olsson L, Rissler M, Castor A, et al. The genomic landscape of high hyperdiploid childhood acute lymphoblastic leukemia. Nat Genet. 2015;47(6):672-6.

21. Zaliova M, Moorman AV, Cazzaniga G, Stanulla M, Harvey RC, Roberts KG, et al. Characterization of leukemias with ETV6-ABL1 fusion. Haematologica. 2016;101(9):1082-93.

22. Zaliova M, Stuchly J, Winkowska L, Musilova A, Fiser K, Slamova M, et al. Genomic landscape of pediatric B-other acute lymphoblastic leukemia in a consecutive European cohort. Haematologica. 2019;104(7):1396-406.

23. Heatley SL, Mayne B, McClure BJ, Kok C, Sadras T, Dang P, et al. Exploring the genomic diversity of AYA and adult high-risk B-ALL cases by mRNA sequencing. EHA Learning Center. 2018; 215242 Abstract.

24. Garrido T, Soares MJ, Barbosa A, Amorim ML, Gomes P, Trigo F, et al. Tirosine kinase rearrangements in Ph-negative acute lymphoblastic leukemia - a FISH approach. EHA Learning Center. 2018; 216176 Abstract.

25. Moorman A, Barretta E, Kirkwood A, Schwab C, Creasey T, Patrick P, et al. Comprehensive screening of B-other adult ALL patients treated on UKALL14 estimates frequency and prognostic impact of gene alterations and identifies JAK-STAT abnormalities as markers of poor outcome. EHA Learning Center. 2018; 214532 Abstract.

26. Russell LJ, Capasso M, Vater I, Akasaka T, Bernard OA, Calasanz MJ, et al. Deregulated expression of cytokine receptor gene, CRLF2, is involved in lymphoid transformation in B-cell precursor acute lymphoblastic leukemia. Blood. 2009;114(13):2688-98.

27. Buitenkamp TD, Pieters R, Gallimore NE, van der Veer A, Meijerink JP, Beverloo HB, et al. Outcome in children with Down's syndrome and acute lymphoblastic leukemia: role of IKZF1 deletions and CRLF2 aberrations. Leukemia. 2012;26(10):2204-11.

28. Chen IM, Harvey RC, Mullighan CG, Gastier-Foster J, Wharton W, Kang H, et al. Outcome modeling with CRLF2, IKZF1, JAK, and minimal residual disease in pediatric acute lymphoblastic leukemia: a Children's Oncology Group study. Blood. 2012;119(15):351222.

29. Harvey RC, Mullighan CG, Chen IM, Wharton W, Mikhail FM, Carroll AJ, et al. Rearrangement of CRLF2 is associated with mutation of JAK kinases, alteration of IKZF1, Hispanic/Latino ethnicity, and a poor outcome in pediatric B-progenitor acute lymphoblastic leukemia. Blood. 2010;115(26):5312-21.

30. Konoplev S, Lu X, Konopleva M, Jain N, Ouyang J, Goswami M, et al. CRLF2-Positive B-Cell Acute Lymphoblastic Leukemia in Adult Patients: A Single-Institution Experience. Am J Clin Pathol. 2017;147(4):357-63.

31. Yoda A, Yoda Y, Chiaretti S, Bar-Natan M, Mani K, Rodig SJ, et al. Functional screening identifies CRLF2 in precursor B-cell acute lymphoblastic leukemia. Proc Natl Acad Sci U S A. 2010;107(1):252-7.

32. Parsa C, Thompson A, Orlando R, Rupani R, Guo J. Novel KMT2A-ATP5L gene fusion in a young adult with rapidly progressive Ph-like $\mathrm{t}(9 ; 12)$ acute B lymphoblastic leukemia. Human Pathology: Case Reports. 2020;20:200359.

33. Heatley SL, Sadras T, Kok CH, Nievergall E, Quek K, Dang P, et al. High prevalence of relapse in children with Philadelphia-like acute lymphoblastic leukemia despite risk-adapted treatment. Haematologica. 2017;102(12):e490-3.

34. Goekbuget N, Beck J, Brueggemann M, Burmeister T, Buss EC, Frickhofen N, et al. Moderate Intensive Chemotherapy Including CNSProphylaxis with Liposomal Cytarabine Is Feasible and effective in Older Patients with Ph-Negative Acute Lymphoblastic Leukemia (ALL): Results of a Prospective Trial From the German Multicenter Study Group for Adult ALL (GMALL). Blood.2012.120:1493.

Page 13/15 
35. Roberts KG, Gu Z, Payne-Turner D, McCastlain K, Harvey RC, Chen IM, et al. High Frequency and Poor Outcome of Philadelphia Chromosome-Like Acute Lymphoblastic Leukemia in Adults. J Clin Oncol. 2017;35(4):394-401.

36. Stock W, Luger SM, Advani AS, Yin J, Harvey RC, Mullighan CG, et al. A pediatric regimen for older adolescents and young adults with acute lymphoblastic leukemia: results of CALGB 10403. Blood. 2019;133(14):1548-59.

37. Lengline E, Beldjord K, Dombret H, Soulier J, Boissel N, Clappier E. Successful tyrosine kinase inhibitor therapy in a refractory B-cell precursor acute lymphoblastic leukemia with EBF1-PDGFRB fusion. Haematologica. 2013;98(11):e146-8.

38. O'Connor D, Moorman AV, Wade R, Hancock J, Tan RM, Bartram J, et al. Use of Minimal Residual Disease Assessment to Redefine Induction Failure in Pediatric Acute Lymphoblastic Leukemia. J Clin Oncol. 2017;35(6):660-7.

39. Moorman A, Schwab C, Kirkwood A, Winterman E, Hancock J, Kearns P, et al. Improved outcome for patients with acute lymphoblastic leukemia (ALL) and an ABL-class fusion following treatment with a tyrosine kinase inhibitor: preliminary data from UKALL2011. EHA Library. 2020. 294937 Abstract.

40. Cario G, Leoni V, Conter V, Attarbaschi A, Zaliova M, Sramkova L. Relapses and treatment-related events contributed equally to poor prognosis in children with ABL-class fusion positive B-cell acute lymphoblastic leukemia treated according to AIEOP-BFM protocols. Haematologica. 2020;105(7):1887-94.

41. Ferrari A, Vitali S, Ghelli Luserna Di Rora A, Baldazzi C, Testoni N, Robustelli V, et al. Unexpected high rate of known and unknown rearrangements in adult triple negative acute lymphoblastic leukemia identified thanks to a efficient transcriptome four tool pipeline anylysys.. EHA Library. 2020. 294277 abstract.

42. Lilljebjörn H, Henningsson R, Hyrenius-Wittsten A, Olsson L, Orsmark-Pietras C, von Palffy S, et al. Identification of ETV6-RUNX1-like and DUX4-rearranged subtypes in paediatric B-cell precursor acute lymphoblastic leukaemia. Nat Commun. 2016;7:11790.

\section{Figures}

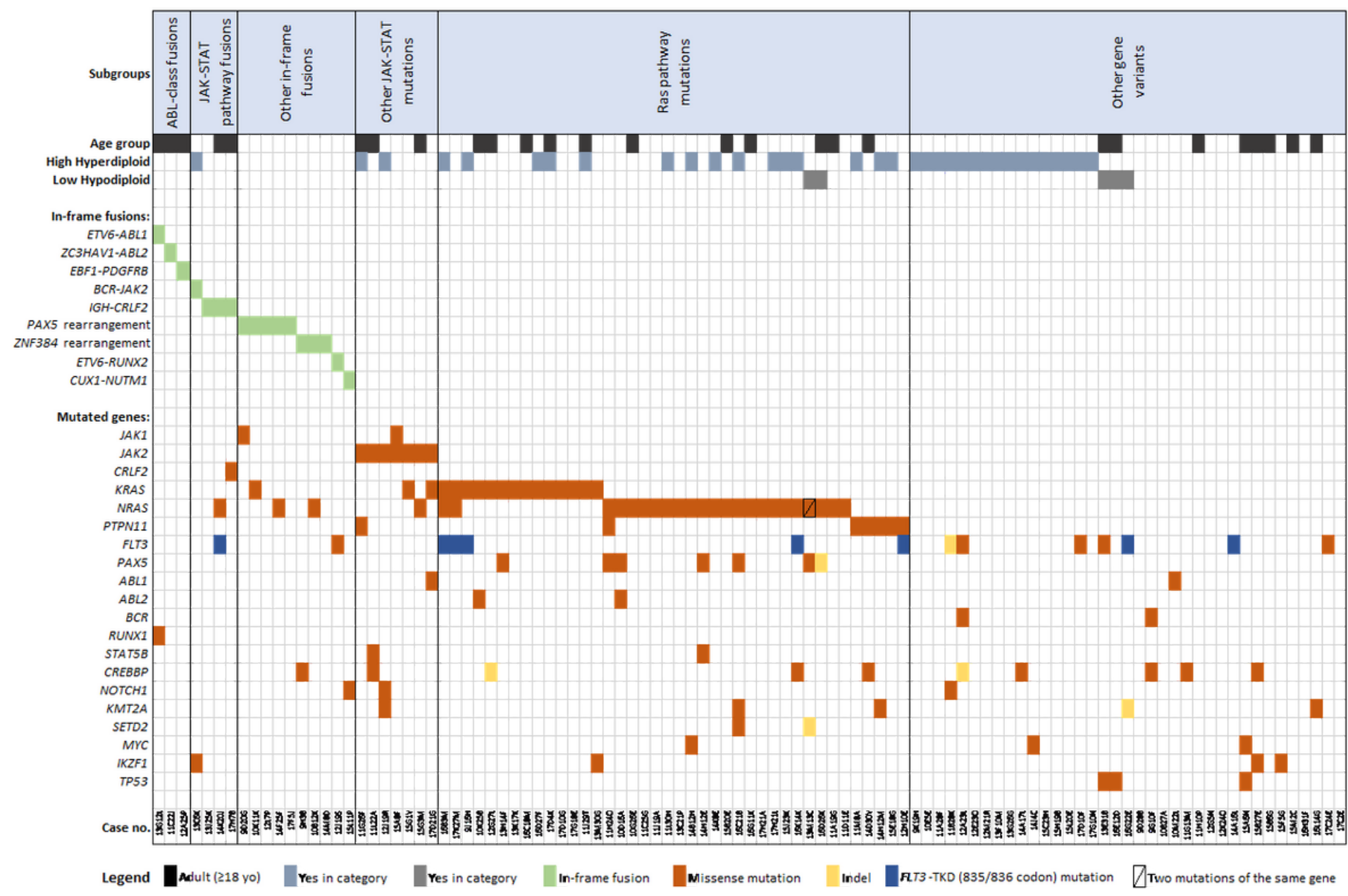

Figure 1

Page 14/15 
Gene fusions and mutations identified by the RNA-Seq method. The cohort is divided into patients with ABL-class fusions, JAK-STAT pathway fusions, other JAK-STAT-activating mutations, Ras pathway mutations, and cases with other or no gene mutations/variants.
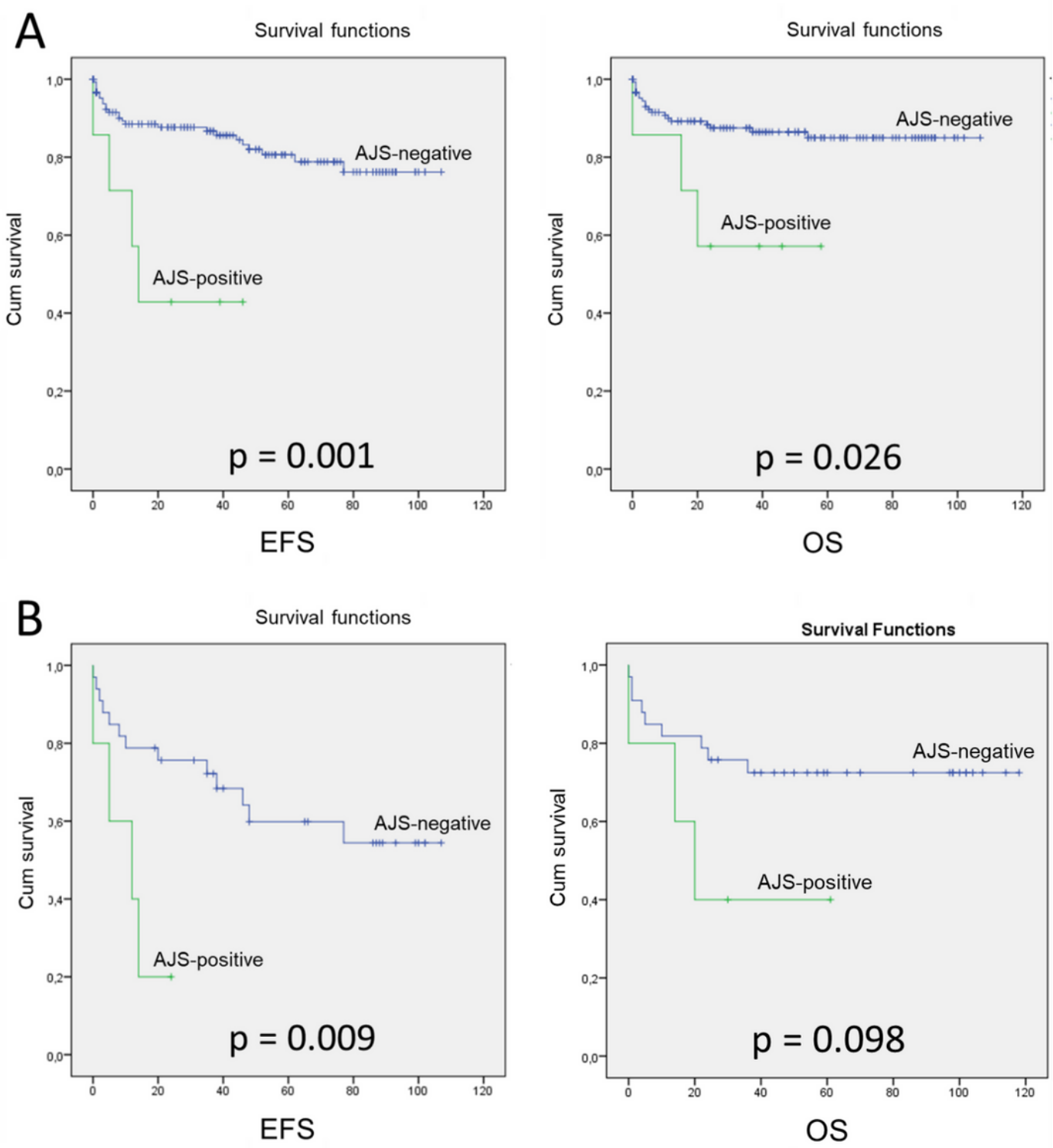

\section{Figure 2}

Event-free survival (EFS) and overall survival (OS) in months in ABL-class or JAK-STAT pathway fusion (AJS)-positive vs. AJS-negative patients. A, all B-ALL patients (7 AJS-positive vs 153 AJS-negative pts); B, adult B-ALL patients (5 AJS-positive vs 33 AJS-negative pts).

\section{Supplementary Files}

This is a list of supplementary files associated with this preprint. Click to download.

- Additionalfile1.pdf 